\title{
A novel evaluation method for dehydrochlorination of plasticized Poly(vinyl chloride) containing heavy metal-free thermal stabilizing synergistic agent
}

\author{
Ali I. Al-Mosawi ${ }^{\circ}$
}

Institute of Ceramic and Polymer Engineering, University of Miskolc, Miskolc, Hungary

\section{Correspondence}

Ali I. Al-Mosawi, Institute of Ceramic and Polymer Engineering, University of Miskolc, Miskolc, Hungary.

Email: aliibrahim76@yahoo.com; alialmosawi76@gmail.com

\begin{abstract}
A novel method for determining the level of dehydrochlorination, that is, the conversion of degradation from the conductivity curve of plasticized Poly(vinyl chloride) (PVC) containing heavy metal-free agent, has been used. The novel method was introduced in this article to evaluate the thermal stability of PVC by dehydrochlorination that shows more reproducibility for measured results than the standard method, which depends on the conductivity only. The novel method was used to measure thermal degradation in a new generation of thermal stabilizing heavy metal-free additive added to plasticized PVC, which is Oxydtron (a nanocement additive). Plasticized PVC containing Oxydtron is our new candidate to replace conventional stabilizers or at least increase their efficiency. The primary use of this new material is in the cable grade industry and construction applications. The basic principle of our novel method is based on converting the conductivity data obtained by the conventional or standard method to $\mathrm{HCl}$ concentration. The data analysis graph will have two curves instead of the one conductivity curve, representing the conversion and $\mathrm{HCl}$ concentration. In this study, a comparison was made between the results of the novel method with the results obtained from the conventional or standard method. In contrast to the standard method, it describes better the process, particularly in the case of PVC compounds. This method's designed computer program shows a good agreement with the discoloration and initial color changes.
\end{abstract}

\section{KEYWORDS}

dehydrochlorination, oxydtron, plasticized PVC

\section{1 | INTRODUCTION}

The thermal degradation of Poly(vinyl chloride) (PVC) does not happen in one step, but actually, it is a sequential dehydrochlorination that leads to creating conjugated polyene sequences. This sequential process goes through three stages: initiation, propagation, and termination. ${ }^{1}$ The initiation of PVC degradation occurs randomly even in case of perfect structure but mostly at the defects created during the polymerization. The most common and important types of polymerization defects are tertiary chlorine atoms resulting from branch formation during polymerization and allylic chlorine atoms formed by termination of the polymerization reaction, as shown in Figure 1.,3 As mentioned, hydrogen chloride is released during the process, which will generate new defects associated with the existing defects arising mainly from polymerization. The releasing of $\mathrm{HCl}$ will continue in a zipper-like fashion when no stabilizer interferes to stop it. After forming $\mathrm{HCl}$ and conjugated double bonds (polyene sequences) a pale yellow color appears when six to seven conjugated double bonds are produced. This pale yellow appearance can turn darker with a growing conjugation length, changing from red to brown and eventually to black. ${ }^{2-9}$

When PVC reaches this stage of releasing $\mathrm{HCl}$, it begins to degrade, which is dangerous not only because it has started to lose its 
FIGURE 1 Degradation of PVC due to heat or shearing at allylic and tertiary chlorine atoms (depending on the data of reference [4])

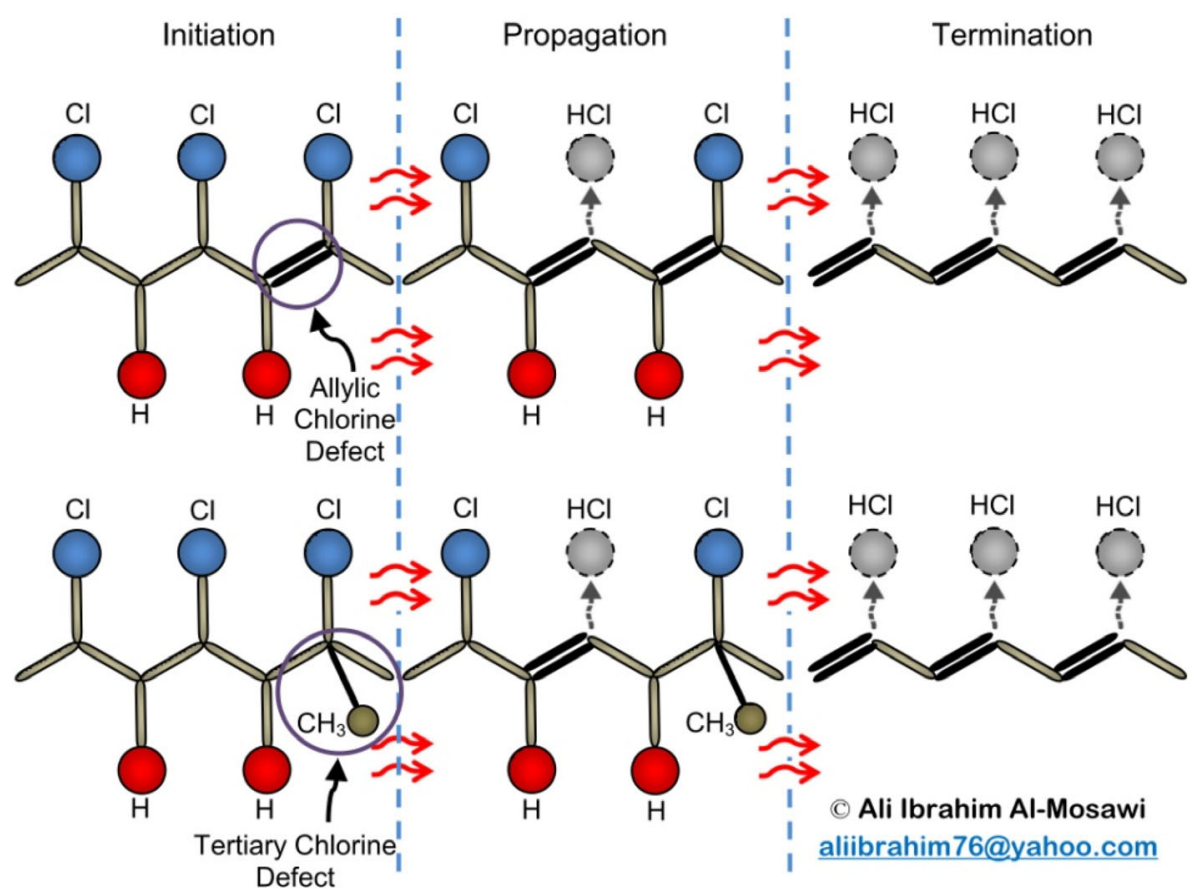

properties, but because degradation products "chlorine compounds" are toxic, which is a danger to human health and leads to environmental pollution. However, the PVC fires are not so huge to consider as an environmental disaster, but it is a danger that cannot be overlooked. ${ }^{10,11}$ Researchers and industrialists attach the issue of degradation in general and thermal degradation, particularly to PVC, due to its significant effects on human safety and the surrounding environment. Therefore, many additives have been developed to reduce and even eliminate the risk of degradation by reducing its toxic products and improving the heat resistance PVC. ${ }^{12-15}$ In addition to this tremendous development of additives, it was necessary to develop mechanisms and programs to measure the amount of degradation and increase its accuracy, which allows obtaining accurate information on studying the behavior of degradation.

\section{2 | METHODOLOGY}

\subsection{Materials}

The percentages of following primary materials used in this study illustrated in Table 1. The description of these materials as follows:

1. PVC suspension type $\mathrm{S}-5070$ (under trademark Ongrovil) produced and supplied by BorsodChemZrt., Hungary.

2. DOP (or DEHP), Bis(2-ethylhexyl) ortho-phthalate plasticizer supplied by DEZA, a. s. CO., Valašské Meziřící, Czech Republic.

3. Calcium-Zinc-based stabilizer (under trademark Newstab-50), which supplied by Betaquímica CO., Barcelona, Spain.

4. Wax-E (under trademark LicowaxE) supplied by Clariant International Ltd, Muttenz Switzerland.
TAB LE 1 Materials used and their percentages

\begin{tabular}{|lll|} 
Component type & Quantity & Unit \\
\hline PVC suspension type S-5070 & 100 & $\mathrm{phr}$ \\
\hline $\begin{array}{l}\text { DOP (or DEHP), Bis(2-ethylhexyl) ortho- } \\
\text { phthalate plasticizer }\end{array}$ & 70 & $\mathrm{phr}$ \\
\hline $\begin{array}{l}\text { Newstab-50, Ca-Zn based stabilizer } \\
\text { Wax E lubricant }\end{array}$ & 1.5 & $\mathrm{phr}$ \\
\hline Oxydtron & 0.3 & $\mathrm{phr}$ \\
\hline & 1,3 and 5 & wt\% \\
\hline
\end{tabular}

5. Oxydtron (type A) supplied by Bioekotech Hungary Kft. Oxydtron is a nanocement admixture applied to concrete to enhance workability and durability properties such as heat resistance, acid/alkali resistance, water leakage resistance, and freezing resistance. The composition of Oxydtron includes many compounds in the form of oxides and carbides such as $\mathrm{Al}_{2} \mathrm{O}_{3}, \mathrm{TiO}_{2}, \mathrm{Fe}_{2} \mathrm{O}_{3}, \mathrm{CaCO}_{3}$, etc., with copolymers such as styrene-butadiene; Vinyl acetate. ${ }^{11,16}$ I could not find anyone who used this nanocement as a polymer additive, especially to improve flame retardancy and thermal stability. Figure 2 illustrates the structure of Oxydtron, which was obtained by using a Carl Zeiss EVO MA10 SEM at the University of Miskolc. Table 2 represents the chemical composition analysis of Oxydtron by using ICP-OES.

\section{2 | Mixing procedure}

There are two types of mixing processes used in this study: primary and secondary mixing as shown in Figure 3. 


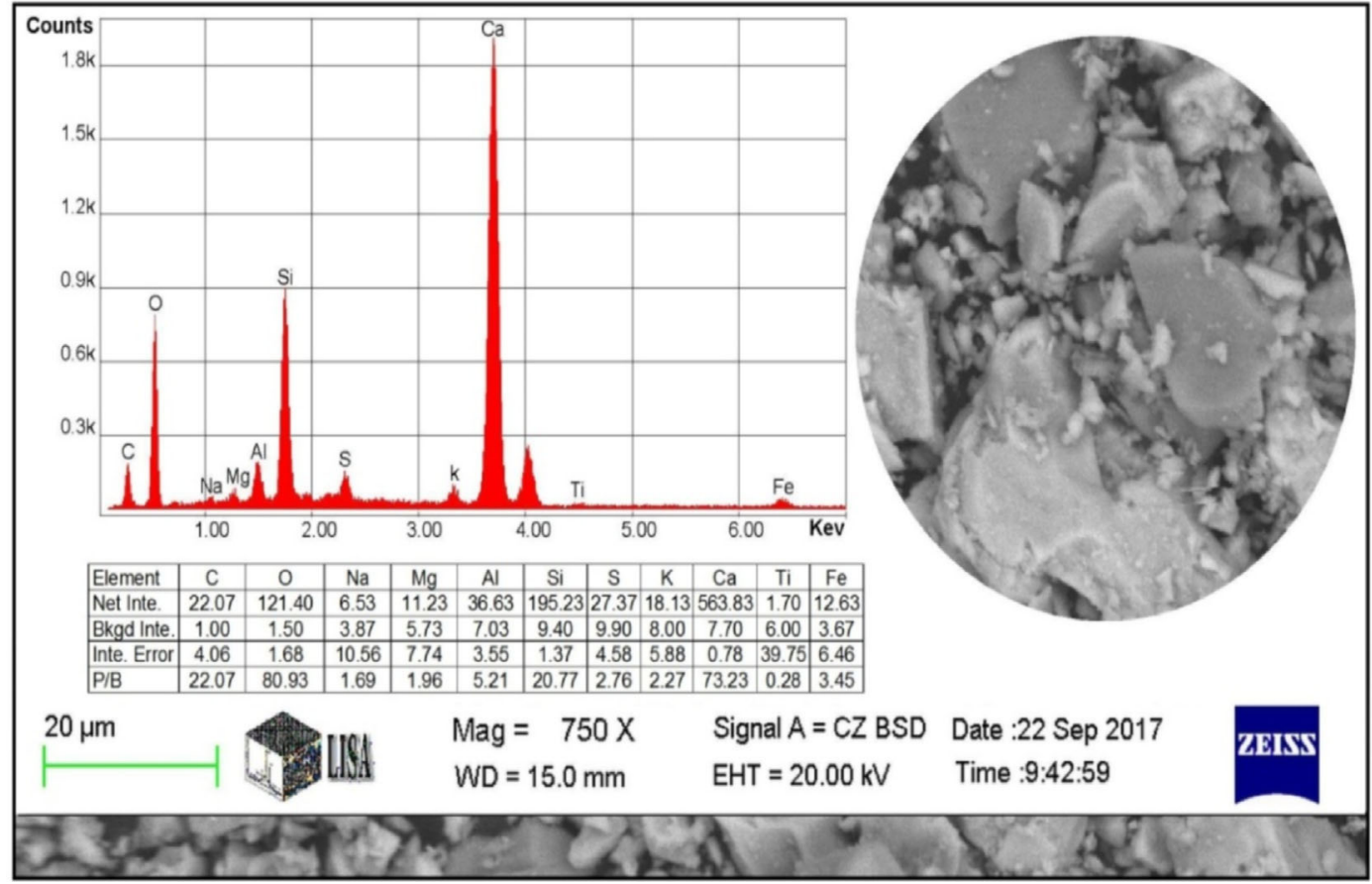

FIG URE 2 SEM-EDAX analysis for Oxydtron

TABLE 2 ICP-OES chemical composition analysis of Oxydtron

\begin{tabular}{lclc} 
Oxide & Ratio, wt\% & Element & Ratio, wt\% \\
$\mathrm{Al}_{2} \mathrm{O}_{3}$ & 4.47 & $\mathrm{Al}$ & 2.37 \\
$\mathrm{CaO}$ & 58.0 & $\mathrm{Ca}$ & 41.4 \\
$\mathrm{Cr}_{2} \mathrm{O}_{3}$ & 0.006 & $\mathrm{Cr}$ & 0.004 \\
$\mathrm{Fe}_{2} \mathrm{O}_{3}$ & 2.67 & $\mathrm{Fe}$ & 1.87 \\
$\mathrm{~K}_{2} \mathrm{O}$ & 0.78 & $\mathrm{~K}$ & 0.65 \\
$\mathrm{MgO}$ & 1.20 & $\mathrm{Mg}$ & 0.72 \\
\hline $\mathrm{Mn}_{2} \mathrm{O}_{3}$ & 0.05 & $\mathrm{Mn}$ & 0.04 \\
$\mathrm{Na}_{2} \mathrm{O}$ & 0.31 & $\mathrm{Na}$ & 0.23 \\
$\mathrm{SO}_{3}$ & 2.50 & $\mathrm{~S}$ & 1.00 \\
$\mathrm{SiO}_{2}$ & 21.44 & $\mathrm{Si}$ & 10.0 \\
$\mathrm{SrO}$ & 0.093 & $\mathrm{Sr}$ & 0.079 \\
$\mathrm{TiO}_{2}$ & 0.274 & $\mathrm{Ti}$ & 0.164 \\
\hline $\mathrm{ZnO}$ & 0.138 & $\mathrm{Zn}$ & 0.111 \\
\hline
\end{tabular}

\subsection{1 | Primary mixing process}

The entire primary mixing process takes about 40 minutes and is accomplished using high-speed fluid mixer type Mischtechnik MTI 10. This process is consists of three stages:

1. Initial mixing: The mixing process starts at a speed of $600 \mathrm{rpm}$, wherein the beginning, the PVC powder (suspension type PVC homopolymer), Ca-Zn based stabilizer, and wax lubricant are mixed together for 2 minutes, then the DOP plasticizer is added to it and mixed all components for 3 minutes.

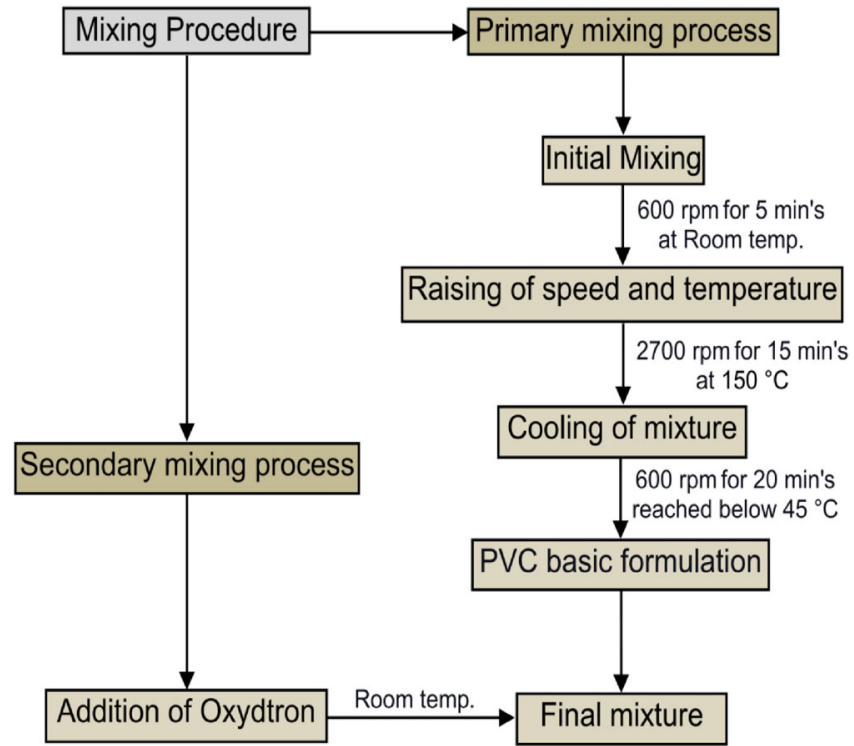

FIGURE 3 Scheme of mixing procedure

2. Raising of speed and temperature: In this stage, the mixing speed increased to $2700 \mathrm{rpm}$. This speed increment causes the temperature of the mixture to rise steadily from room temperature and reaching to $150^{\circ} \mathrm{C}$, due to the shearing of particles between the components. The mixture stays at $2700 \mathrm{rpm}$ for about 15 minutes while the temperature rises to $150^{\circ} \mathrm{C}$. The stability of speed allows the plasticizer to penetrate PVC particles further to obtain a homogenized structure with optimum production characteristics. 
3. Cooling of mixture: In order to cool the mixture, the mixing speed is reduced to $600 \mathrm{rpm}$ and stays at this steady speed for 20 minutes. During a constant speed period, the temperature of the mixture will drop below $45^{\circ} \mathrm{C}$. At the end of this stage, the temperature of the mixture reaches $30^{\circ} \mathrm{C}$.

\subsection{2 $\quad$ Secondary mixing process}

This process involves applying Oxydtron to the PVC basic formulation mixture produced by the primary mixing process with various weight fractures $(1,3$, and 5 wt\%). This new mixture is mixed by a small

TABLE 3 Processing conditions of test samples

\begin{tabular}{|c|c|c|c|c|c|}
\hline \multicolumn{4}{|c|}{ Processing temperature, ${ }^{\circ} \mathrm{C}$} & \multirow[b]{2}{*}{$\begin{array}{l}\text { Pressure, } \\
\text { bar }\end{array}$} & \multirow[b]{2}{*}{$\begin{array}{l}\text { Speed, } \\
\text { rpm }\end{array}$} \\
\hline $\begin{array}{l}\text { Zone } \\
1\end{array}$ & $\begin{array}{l}\text { Zone } \\
2\end{array}$ & $\begin{array}{l}\text { Zone } \\
3\end{array}$ & $\begin{array}{l}\text { Zone } \\
4\end{array}$ & & \\
\hline 125 & 130 & 135 & 140 & 100 & 60 \\
\hline
\end{tabular}

TABLE 4 Components of test samples

\begin{tabular}{ll} 
Sample No. & Content \\
\hline Sample 1 & PVC basic formulation \\
\hline Sample 2 & PVC +1 wt\% Oxydtron \\
\hline Sample 3 & PVC $+3 w t \%$ Oxydtron \\
\hline Sample 4 & PVC $+5 w t \%$ Oxydtron \\
\hline
\end{tabular}

electrical mixer for 1 minute to uniformly dispersed and homogenized Oxydtron into the mixture.

\section{3 | Sample preparation}

The dehydrochlorination test samples were prepared as pellets with $3 \mathrm{~mm}$ diameter and about $2 \mathrm{~mm}$ thickness at uniform conditions as listed in Table 3. Counter-rotating twin-screw extrusion machine type Schloemann

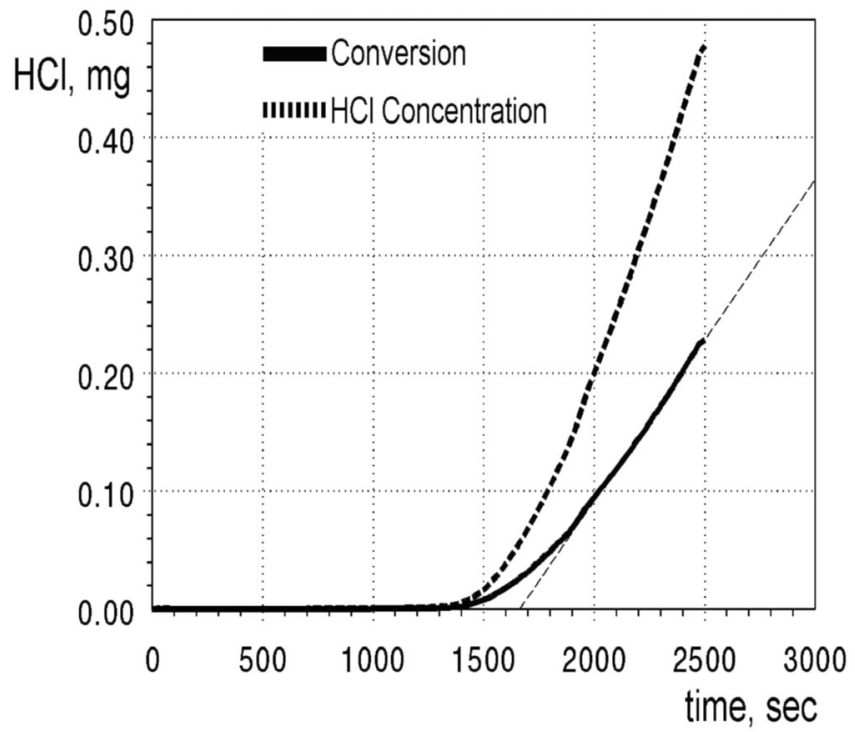

FIGURE 5 Dehydrochlorination test for plasticized PVC basic formulation at $190^{\circ} \mathrm{C}$ by novel method

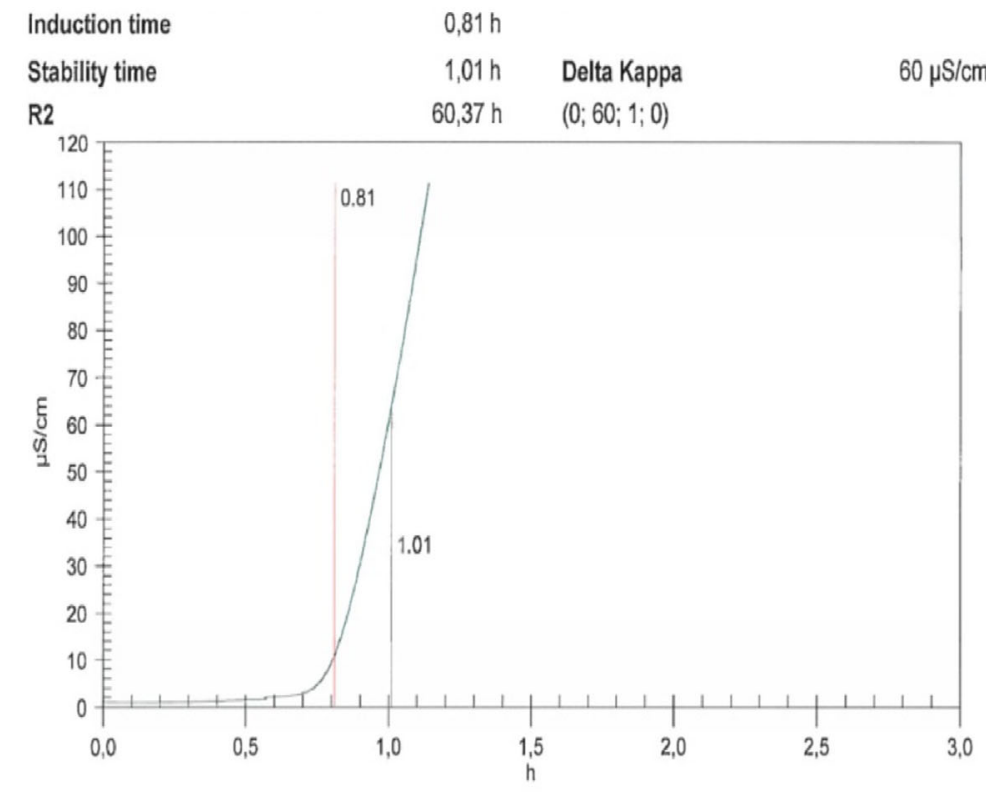

(A)

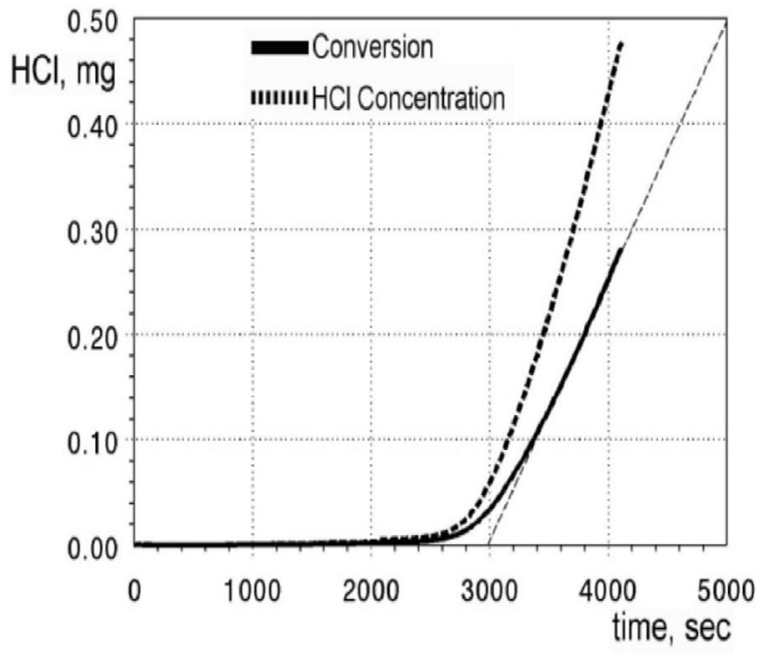

(B)

FIGURE 4 The standard method graph A, is compared to the novel method graph B, to calculate the thermal stability, that is, the dehydrochlorination rate 


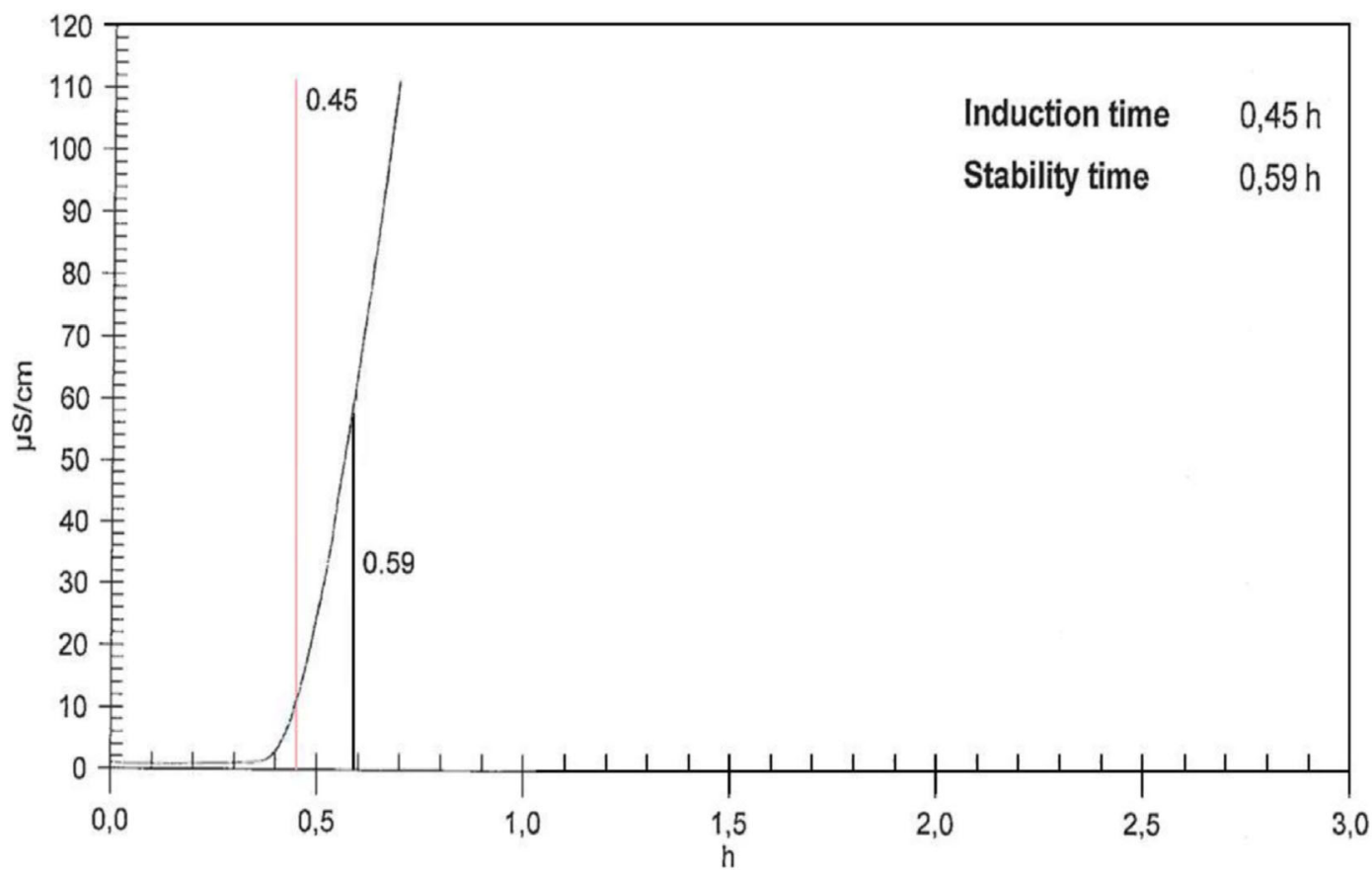

FIG URE 6 Conductivity of plasticized PVC basic formulation at $190^{\circ} \mathrm{C}$ by standard method

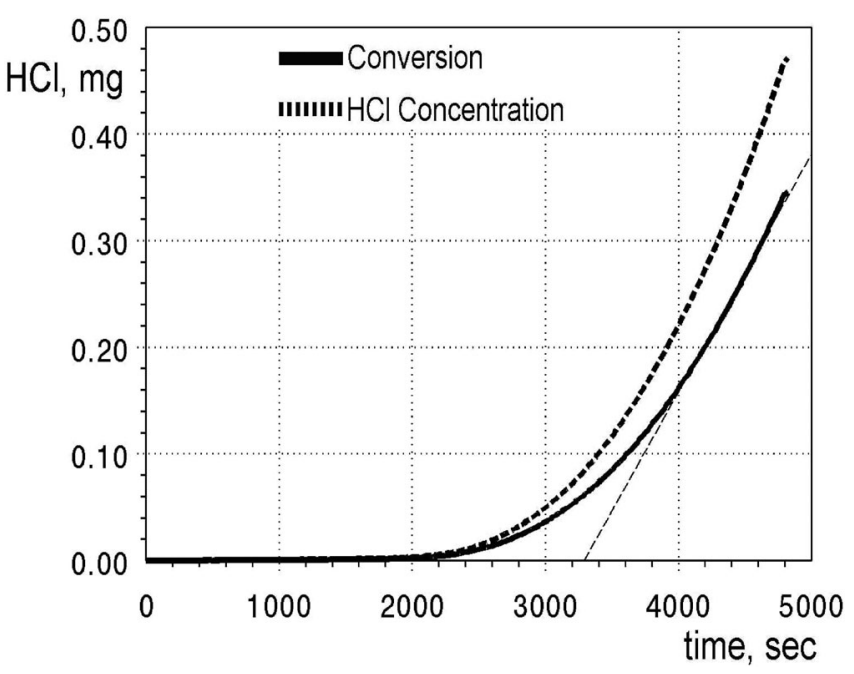

FIGURE 7 Dehydrochlorination test of plasticized PVC containing $1 \mathrm{wt} \%$ Oxydtron at $190^{\circ} \mathrm{C}$ by novel method

BT-50 was used to produce these samples, and all preparation steps have been completed at BorsodChem Zrt., Hungary. The extrusion process is not completed in one stage but instead passes through four stages, where the extrusion machine contains four zones with different temperatures. Four blends of plasticized PVC had been made, as shown in Table 4.

\section{4 | Dehydrochlorination test}

Two methods were used to evaluation of dehydrochlorination rates $\mathrm{n}$ as follows.

\subsection{1 | Standard method}

Dehydrochlorination rates have been measured by Metrohm 763 Thermomat found also at BorsodChem Zrt., Hungary. This test was carried out according to ISO $182-3: 1993$ standard $^{17}$ at $190^{\circ} \mathrm{C}$. This method involves exposing the PVC samples inside device to high temperatures to measure the stability time (the time until PVC begins to release hydrogen chloride). ${ }^{18}$ Stability time determined as time to $60 \mu \mathrm{S} / \mathrm{cm}$ conductivity, which means about $0.9 \%$ conversion of dehydrochlorination.

\subsection{2 | Novel evaluation method}

I collected the data stored in the device database after performing each test. Then I analyzed it by a program to get more even kinetic information from the dehydrochlorination tests. The method of analysis is as follows:

a. The conductivity can be converted to $\mathrm{HCl}$ concentration. The conversion function is calculated from the Equation (1) depending on Foxboro data table ${ }^{19}$ as follows:

$$
\log (c)=-1.05788+0.9882 \times \lg (k)+0.003988 \times(\lg (k))^{2}
$$

where

c: $\mathrm{HCl}$ concentration in $\mathrm{mg} / \mathrm{L}$.

$k$ : specific conductivity in $\mu \mathrm{S} / \mathrm{cm}$.

If the absorbent water quantity is known the $\mathrm{HCl}$ weight $(\mathrm{mg})$ can also be calculated. The instrument is using $50 \mathrm{~mL}$ water, so the absorbed $\mathrm{HCl}$ is $\mathrm{c} / 20$. 


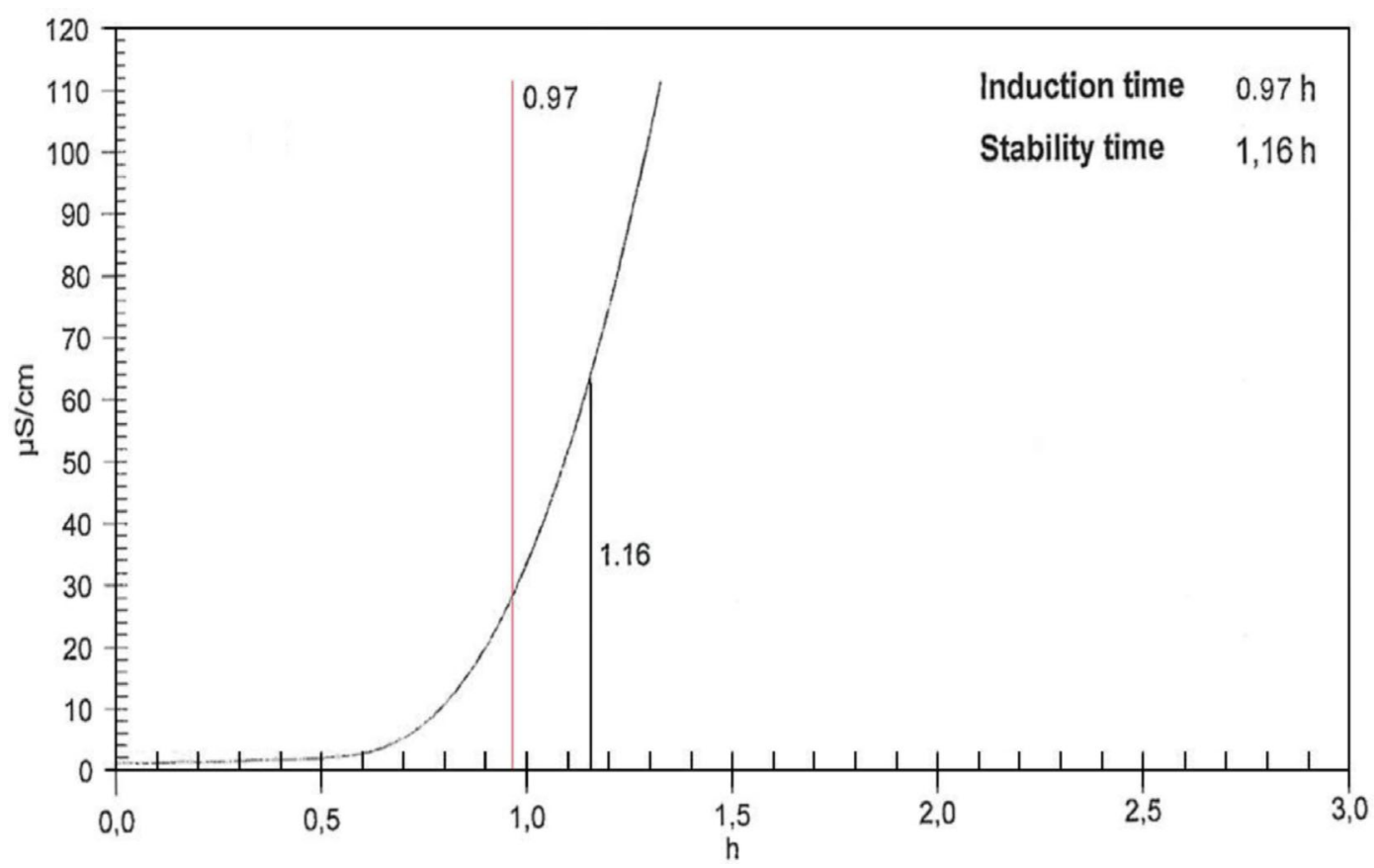

FIGURE 8 Conductivity of plasticized PVC containing 1 wt\% Oxydtron at $190^{\circ} \mathrm{C}$ by standard method

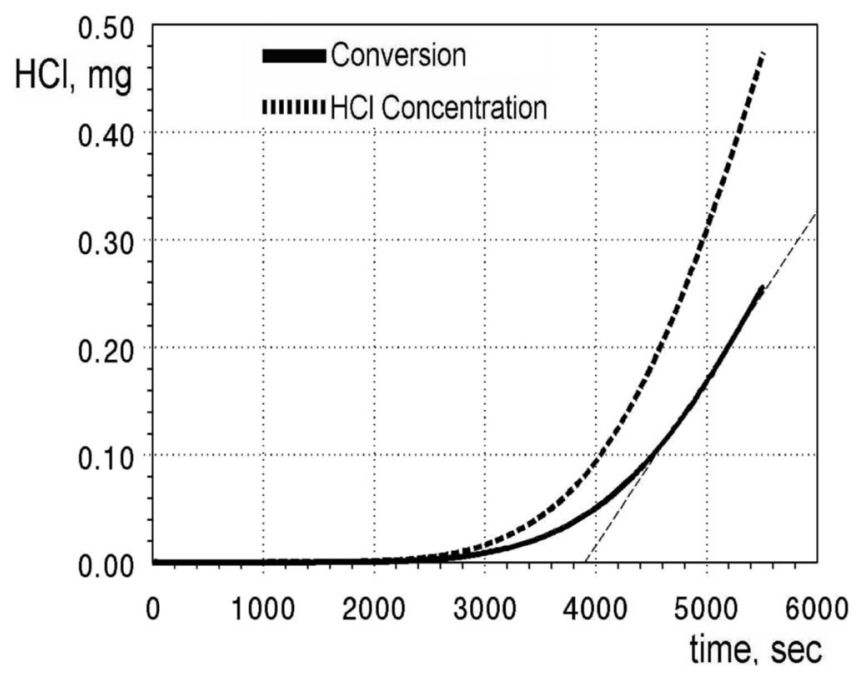

FIGURE 9 Dehydrochlorination test of plasticized PVC containing $3 \mathrm{wt} \%$ Oxydtron at $190^{\circ} \mathrm{C}$ by novel method

b. If the exact mass of PVC ( $\left.m_{\mathrm{PVC}}\right)$ in the sample is known, the dehydrochlorination curve can be converted to the conversion of degradation. Because from pure PVC $58.4 \% \mathrm{HCl}$ is evolved during total degradation, the conversion ( $k_{\text {conv. }}$ ) is:

$$
k_{\text {conv. }}=m_{\mathrm{HCl}} / 0.584 \times m_{\mathrm{PVC}}
$$

The difference between the standard method and the Novel method in calculating the dehydrochlorination rate is shown in Figure 4.

\section{RESULTS AND DISCUSSION}

When the temperature is higher than average, the crystalline structure of PVC becomes less stable, leading to strongly releasing chlorinecontaining compounds $(\mathrm{HCl})$. As a result, PVC resistance begins to decrease. The amount of $\mathrm{HCl}$ release also depends on the period of exposure to such elevated temperatures. Where the more extended the period, the more severe the $\mathrm{HCl}$ removal. Figures 5 and 6 represent a dehydrochlorination and conductivity test for plasticized PVC basic formulation at $190^{\circ} \mathrm{C}$ estimated by novel and standard method. Figure 5 (novel method) shows that the $\mathrm{HCl}$ removal is very rapid, increasing exposure to high temperature after a state of stability. And the curve slope is very sharp (high inclination). While for the results obtained in the standard method shown in Figure 6, which depends on measuring the conductivity, we note that the induction time and stability time were short, and their values ranged between 0.45 and 0.59 hour, respectively, which means that the thermal stability of PVC is significantly reduced at high temperatures. ${ }^{20,21}$

This is normal behavior for all polymers, including PVC, due to their low thermal resistance at elevated temperatures. So, at the initiation stage of dehydrochlorination, the structural segments of PVC will release $\mathrm{HCl}$, and this causes these structural segments to turn into allylic chloride groups. This thermal resistance of PVC decreases more and more as the release of $\mathrm{HCl}$ increases where the crystalline structure of PVC is strongly deformed. When the first stage is not obstructed, the degradation will enter the second stage, propagation. In this stage, the allylic chloride groups will begin to elongate rapidly and be converted into polyenes as the degradation process progresses. ${ }^{1}$ The dehydrochlorination will reach the third stage, which is 


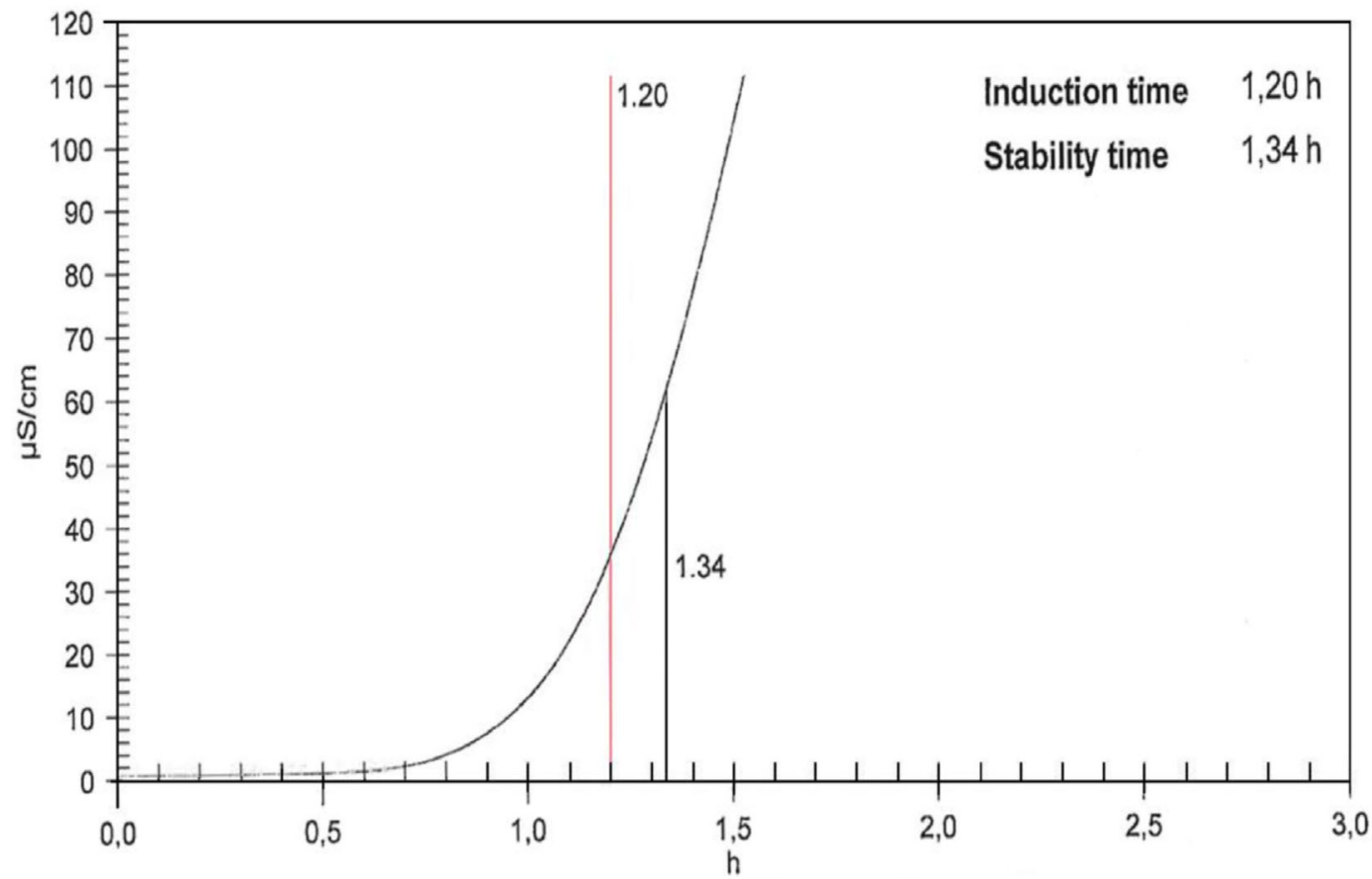

FIGURE 10 Conductivity of plasticized PVC containing 3 wt\% Oxydtron at $190^{\circ} \mathrm{C}$ by standard method

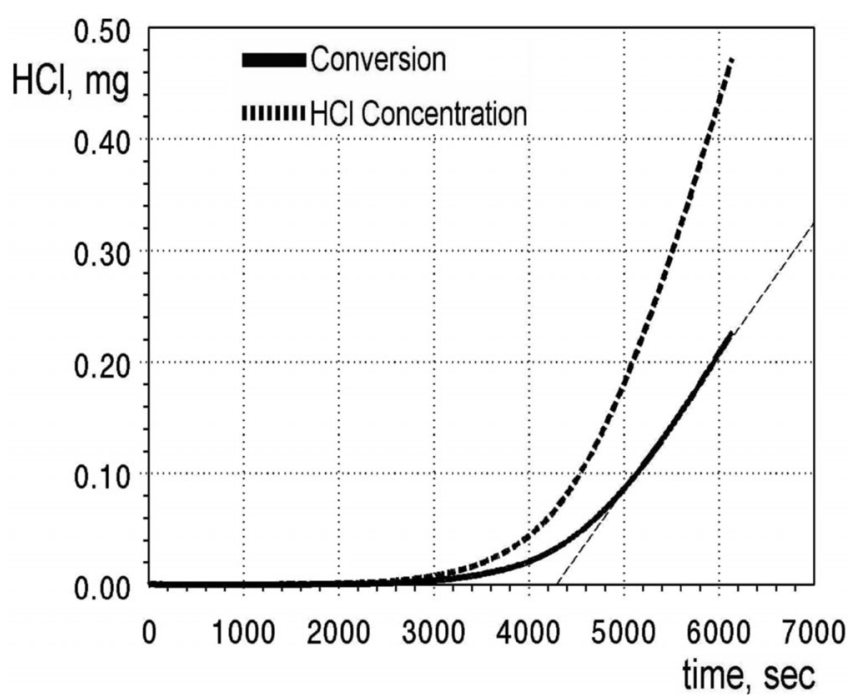

FIGURE 11 Dehydrochlorination test of plasticized PVC containing $5 \mathrm{wt} \%$ Oxydtron at $190^{\circ} \mathrm{C}$ by novel method

termination, where the bonds between atoms begin to break down, and a significant amount of chlorine-containing compounds are released. Finally, the material will be completely burnt. ${ }^{1,22}$ This is observed from the high slope of the curve $\left(272 \times 10^{-6}\right)$, and at this point, the PVC reached the degree of total degradation. The time for break down at $190^{\circ} \mathrm{C}$ is (0.694 hour).

As is known, the thermal stability of any polymer, including PVC can be modified by additives, ${ }^{23}$ where the thermal stability of crystalline structure of PVC at high temperatures has been improved after the inclusion of Oxydtron as seen in Figures 7 and 8 represent a dehydrochlorination and conductivity test for plasticized PVC containing 1 wt\% Oxydtron at $190^{\circ} \mathrm{C}$ estimated by novel and standard method. The curve slope of Figure 7 at test temperature has been reduced to $\left(223 \times 10^{-6}\right)$ after the addition of Oxydtron, and the time of degradation was increased to (1.34 hours). As a comparison with this figure and Figure 8 , which was calculated using the standard method, we also notice an increase in the stability time to 1.16 hours, and the induction time was 0.97 hour. This indicates that the PVC has become more stable. The propensity to release $\mathrm{HCL}$ has reduced, reflecting a significant change in the structure of PVC since the addition of Oxydtron. From our point of view, and depending on the results we obtained, the Oxydtron will hinder the formation of allylic chloride groups, which will lead to the prevention of polyenes formation, and delay the PVC entering the propagation stage. Thus the fire will be extinguished.

As the weight fraction of Oxydtron additives rises to $3 \mathrm{wt} \%$, the thermal resistance stability of plasticized PVC will increase, and this activity can be differentiated by Figures 9 and 10, which represents the dehydrochlorination and conductivity test for plasticized PVC containing $3 \mathrm{wt} \%$ Oxydtron at $190^{\circ} \mathrm{C}$ estimated by novel and standard method, respectively. From Figure 9, we can note that the slope of the conversion rate curve decreases, meaning that the resistance to degradation has improved, whereby, in this case, the conversion rate is reduced to $\left(155 \times 10^{-6}\right)$ as opposed to the previous figure with a rise in overall degradation time to (1.533 hours). As for Figure 10, it can be seen the significant improvement in the conductivity of PVC, as both the induction time and the stability time increased to 1.20 and 1.34 hours, respectively. This incremental increase of thermal stability 


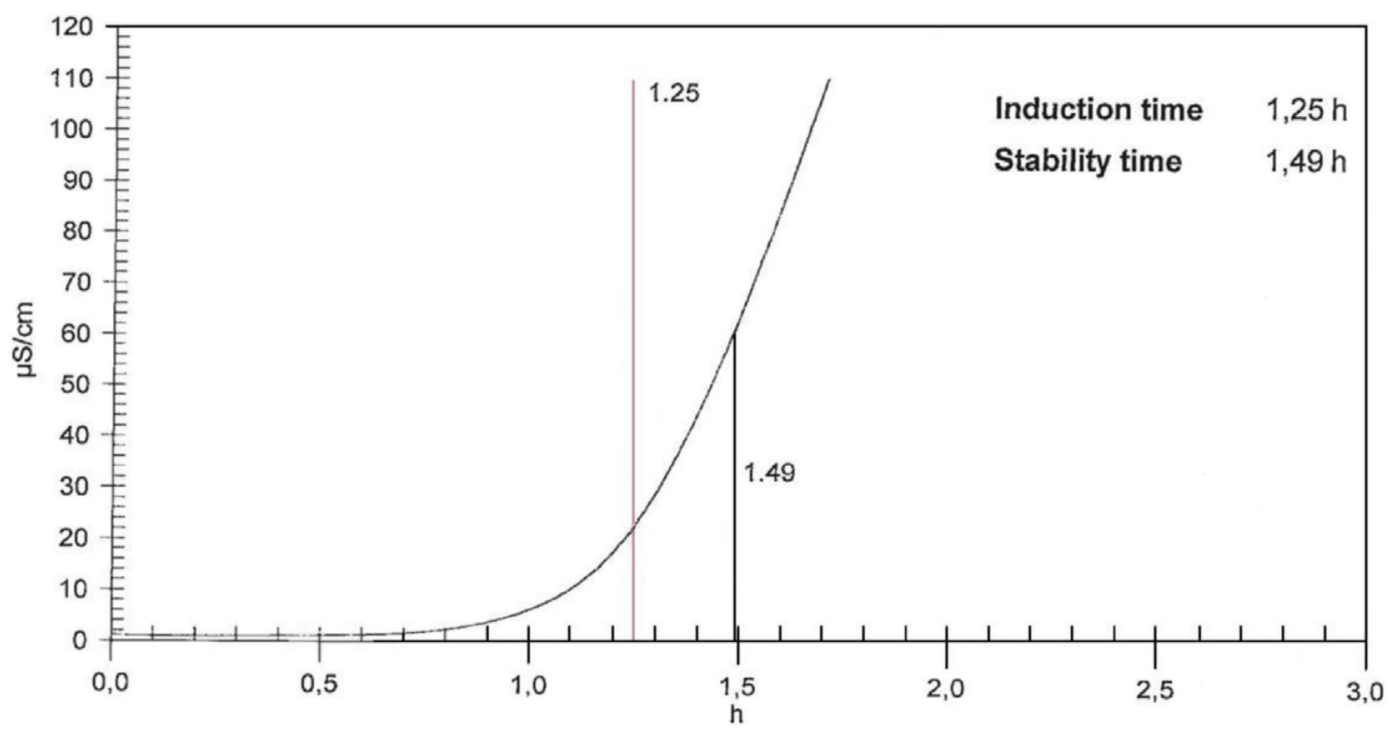

FIGURE 12 Conductivity of plasticized PVC containing 5 wt\% Oxydtron at $190^{\circ} \mathrm{C}$ by standard method

TAB LE 5 Slopes values of dehydrochlorination test at $190^{\circ} \mathrm{C}$ measured by novel method

\begin{tabular}{|ll|}
\hline Material & Slope, $10^{-6} \% \mathrm{~s}^{-1}$ \\
\hline PVC basic formulation & 272 \\
\hline PVC +1 wt\% Oxydtron & 223 \\
\hline PVC $+3 w t \%$ Oxydtron & 155 \\
\hline PVC +5 wt\% Oxydtron & 120 \\
\hline
\end{tabular}

TAB LE 6 Induction time and stability time of PVC containing Oxydtron at $190^{\circ} \mathrm{C}$ measured by standard method

\begin{tabular}{|lll|}
\hline Material & $\begin{array}{l}\text { Induction } \\
\text { time, hour }\end{array}$ & $\begin{array}{l}\text { Stability } \\
\text { time, hour }\end{array}$ \\
\hline PVC basic formulation & 0.45 & 0.59 \\
\hline $\begin{array}{c}\text { PVC }+1 \text { wt\% } \\
\text { Oxydtron }\end{array}$ & 0.97 & 1.16 \\
\hline $\begin{array}{c}\text { PVC }+3 w t \% \\
\text { Oxydtron }\end{array}$ & 1.20 & 1.34 \\
\hline $\begin{array}{c}\text { PVC }+5 w t \% \\
\text { Oxydtron }\end{array}$ & 1.25 & 1.49 \\
\hline
\end{tabular}

TAB LE 7 Improvement percentage of DHC time for plasticized PVC containing Oxydtron at $190^{\circ} \mathrm{C}$ by novel method

\begin{tabular}{|lllll} 
Material & PVC & $\begin{array}{l}\text { PVC }+1 \% \\
\text { Oxydtron }\end{array}$ & $\begin{array}{l}\text { PVC }+3 \% \\
\text { Oxydtron }\end{array}$ & $\begin{array}{l}\text { PVC }+5 \% \\
\text { Oxydtron }\end{array}$ \\
\hline $\begin{array}{c}\text { DHC time, } \\
\text { hour }\end{array}$ & 0.694 & 1.340 & 1.533 & 1.710 \\
$\begin{array}{c}\text { Improvement } \\
\text { percentage }\end{array}$ & - & $93.1 \%$ & $120.9 \%$ & $146.4 \%$ \\
\hline
\end{tabular}

values is due to the growing synergistic action between the PVC and the Oxydtron.

The thermal resistance of PVC will increase with the increased proportion of Oxydtron and this is evident through Figures 11 and 12 which represents the dehydrochlorination and conductivity test for plasticized PVC containing 5 wt\% Oxydtron at $190^{\circ} \mathrm{C}$ estimated by novel and standard method respectively. Figure 11 reveals that the curve continues to steadily grow with a low slope, which means that a decline in the degradation rate can be seen in which the conversion rate has been slope $\left(120 \times 10^{-6}\right)$ and the degradation period has been increased to (1.71 hour). This increase in thermal resistance is also visible in Figure 12, where the induction time and the stability time are increased to 1.25 and 1.49 hours, respectively.

As a summary and comparison of the two methods, we have arranged the results in tables. Table 5 represents the novel method's slope values, and Table 6 describes the induction time and stability time of PVC containing Oxydtron at $190^{\circ} \mathrm{C}$ measured by the standard method. As we note, the results obtained from the novel method are more accurate than the standard method. A summary of the improvement percentage of DHC time for plasticized PVC containing Oxydtron shows in Table 7.

\section{4 | CONCLUSIONS}

The critical points obtained from the tests performed on plasticized PVC (basic formulation and containing Oxydtron) will be summarized as follows: Because PVC-based compounds might contain different amounts of PVC, the standard method cannot be used for comparing different compounds. $60 \mu \mathrm{S} / \mathrm{cm}$ specific conductivity represents the same amount of $\mathrm{HCl}$ but different degradation grade. Using only this method leads to misleading results. Although the method based on 
real dehydrochlorination conversion gives shorter stability times than the standard, the excellence of Oxydtron is proven. The degradation characteristic of Oxydtron containing compounds evaluated by the new procedure shows better agreement with other, for example, discoloration methods. It is worth introducing the conversion based method for all PVC compounds.

\section{ACKNOWLEDGEMENT}

After completing my article, I extend my thanks and pride to Irén Buzellákné Pető and Csaba Kónya at the BorsodChem Zrt., Árpád Kovacs at SEM laboratory, University of Miskolc for their assistance.

\section{DATA AVAILABILITY STATEMENT}

The data that support the findings of this study are available from the corresponding author upon reasonable request.

\section{ORCID}

Ali I. Al-Mosawi DiD https://orcid.org/0000-0002-8688-3208

\section{REFERENCES}

1. Starnes WH, Ge X. Mechanism of autocatalysis in the thermal dehydrochlorination of poly(vinyl chloride). Macromolecules. 2004;37(2): 352-359.

2. Hjertberg, T, Sörvik, EM. Formation of anomalous structures in PVC and their influence on the thermal stability:1. Endgroup structures and labile chlorine substituted by phenol, J Macromol Sci A 1982; 17 (6): 983-1004, Published online: 05 Dec 2006.

3. Hjertberg T, Sörvik EM. Formation of anomalous structures in PVC and their influence on the thermal stability: 2. Branch structures and tertiary chlorine. Polymer. 1983;24(6):673-684.Available online 24 April 2003.

4. Schiller M. PVC Additives: Performance, Chemistry, Developments, and Sustainability. 1st ed. Germany: Hanser; 2015.

5. Hjertberg T, Sörvik EM. Formation of anomalous structures in PVC and their influence on the thermal stability: 3 . Internal chloroallylic groups. Polymer. 1983;24(6):685-692.Available online 24 April 2003.

6. Jurriaan C, Heuvel M, Weber AJM. End groups in poly(vinyl chloride) and their influence on the thermal stability. Macromol Chem Phys. 1983;184(11):2261-2273.

7. Michel A. PVC thermal stability assessment using tests in the presence of stabilizers. J Vinyl Addit Technol. 1985;7(2):77-91.

8. Guyot A. Working party on defects in the molecular structure of polyvinylchloride and their relation to thermal stability: general conclusions. J Vinyl Addit Technol. 1985;7(2):92-94.

9. Michel A. Working party on defects in the molecular structure of polyvinylchloride and their relation to thermal stability: general introduction. J Vinyl Addit Technol. 1985;7(2):46-52.
10. Al-Mosawi Al, Marossy K. Elimination of plasticized poly(vinyl chloride) degradability by using oxydtron: a novel study. ARPN J Eng Appl Sci. 2020;15(3):405-411.

11. Al-Mosawi Al, Marossy K. Heavy metal free thermal stabilizing-flame retarding modifier for plasticized poly(vinyl chloride). Mater Res Express. 2020;7(1):015320.

12. Lu Y, Wang B, Xue M-Y, Lu Y-W. Kinetics of thermal oxidative degradation of poly (vinyl chloride) containing $\mathrm{Ca}$ and $\mathrm{Sn}$ at low temperature. Waste Manag. 2021;121:52-58.

13. Al-Mosawi Al, Marossy K. Thermal stability and flame retardant properties of plasticized poly(vinyl chloride) hybrid composite for construction application. Építőanyag. 2019;71(6):198-203.

14. Korkusuz Ç, Demir APT. Evaluation of the thermal stabilization behavior of hydrotalcite against organic stabilizers for plasticized PVC films. Polym Bull. 2020;77(9):4805-4831.

15. Wang B, Lu Y-H, Lu Y-W. Organic tin, calcium-zinc and titanium composites as reinforcing agents and its effects on the thermal stability of polyvinyl chloride. J Therm Anal Calorim. 2020;142(2):671-683.

16. Dunuweera SP, Rajapakse RMG. Cement types, composition, uses and advantages of nanocement, environmental impact on cement production, and possible solutions. Adv Mater Sci Eng. 2018;2018:4158682.

17. ISO 182-3:1993. Plastics-Determination of the Tendency of Compounds and Products Based on Vinyl Chloride Homopolymers and Copolymers to Evolve Hydrogen Chloride and Any Other Acidic Products at Elevated Temperatures-Part 3: Conductometric Method. Switzerland: International Organization for Standardization (ISO); 1993.

18. PVC Thermomat. Hungary: Metrohm Magyarország Kft.; 2018.

19. Table of Conductivity vs Concentration for Common Solutions. Foxboro, MA: Invensys/Foxboro; 1999.

20. Taubinger RP, Allsopp MW, Vander Loo HJM, Mooij JJ. Measuring the heat stability of PVC by dehydrochlorination. Polym Test. 1986;6 (5):337-350.

21. Han W, Zhang M, Li D, et al. Design and synthesis of a new mannito stearate ester-based aluminum alkoxide as a novel tri-functional additive for poly(vinyl chloride) and its synergistic effect with zinc stearate. Polymers. 2019;11(6):1031.

22. Zheng X-G, Tang L-H, Zhang N, et al. Dehydrochlorination of PVC materials at high temperature. Energy Fuels. 2003;17(4):896-900.

23. Palin L, Rombolà G, Milanesio M, Boccaleri E. The use of poss-based nanoadditives for cable-grade PVC: effects on its thermal stability. Polymers. 2019;11(7):1105.

How to cite this article: Al-Mosawi Al. A novel evaluation method for dehydrochlorination of plasticized Poly(vinyl chloride) containing heavy metal-free thermal stabilizing synergistic agent. Polym Adv Technol. 2021;32:3278-3286. https://doi.org/10.1002/pat.5339 